\title{
COMPENSATION OF VOLTAGE LOSS IN THE POWER LINE
}

\author{
MALAFEEV, S.I. \& MALAFEEV, S.S.
}

Abstract: The method of compensating voltage loss in the electrical network providing high power load are considered. Compensation is achieved by maintaining a capacitive (or inductive) current in the supply network using the high speed compensating device. The required value of current is determined by the compensator by calculations based on measurements of the active and reactive load current and load voltage in the node. Active and inductive impedance supply mains assumed to be known or identified in the process. The equations for calculating currents in the power supply system for a variety of modes are proposed.

Key words: voltage, compensation, reactive current, regulation.
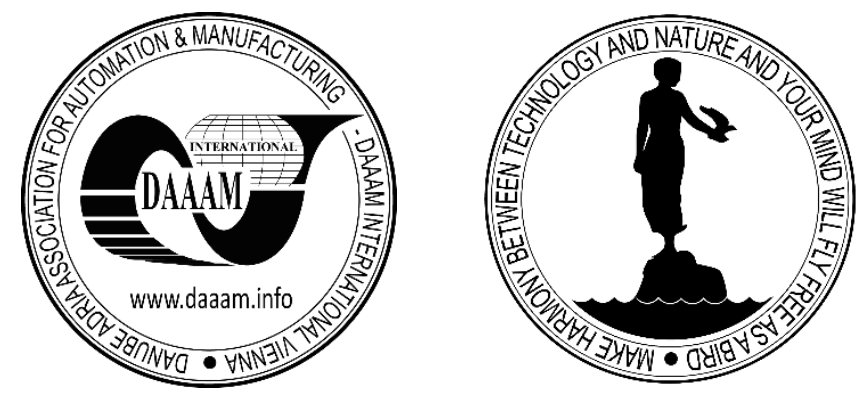

Authors' data: Prof., Doctor of Sciences (eng.), Malafeev, S[ergey] I.*; Ph.D (eng.) Malafeev, S[ergey] S.**, *Joint Power Co, Ltd., P.o. 33, 111672, Moscow, Russia, **Vladimir Polytechnic College, Oktiabrskiy pr. 11, 600025, Vladimir, Russia, sim_vl@nm.ru,cerg87@gmail.ru

This Publication has to be referred as: Malafeev, S[ergey] I[. \& Malafeev, S[ergey] S. (2018). Compensation of Voltage Loss in the Power Line, Chapter 28 in DAAAM International Scientific Book 2018, pp.317-324, B. Katalinic (Ed.), Published by DAAAM International, ISBN 978-3-902734-19-8, ISSN 1726-9687, Vienna, Austria

DOI: $10.2507 /$ daaam.scibook.2018.28 


\section{Introduction}

In the extractive industry, in many cases, power is used for individual highpower consumers, for example, mechatronic complexes of mining machines, from a central substation using long lines (Morley, 1990). The voltage drop in the supply line leads to a decrease in the quality of electrical energy in the load node. When powerful mechatronic systems, for example, mining excavators operate, not only consumption but also energy recuperation occurs (Malafeev \& Novgorodov, 2016). This leads to an increase in the voltage in the mains. Therefore, for effective use of the energy resource of mechatronic complexes, it is necessary to use special methods and tools aimed at reducing voltage and power losses, improving the quality of electric power and ensuring electromagnetic compatibility of electrical equipment.

To increase the efficiency of energy transfer from source to consumer, the following basic methods are used:

- the use of compensating devices to increase the power factor and the quality of electrical energy (Rogobete \& Dumitrascu, 2016);

- use of active rectifiers in the structure of high-power electric drives (Pandit et al., 2010);

- use of algorithms for controlling electric drives providing the necessary electromagnetic compatibility of equipment, for example, "soft" starting of engines (Malafeev \& Serebrennikov, 1996).

Compensating devices of various types represent the main means of increasing the efficiency of power supply systems with high-power loads. At present, capacitor batteries, thyristor-reactor compensators, Static Synchronous Compensators and others are widely used (Dixon et al., 2005).

For control of the compensating devices, classical automatic feedback control systems are used (Vasileviccs \& Rankis, 2012). New control algorithms based, for example, on fuzzy logic (Singh \& Sharma, 2015) are also applied.

Maintaining in the electrical system of regimes ensuring the effective use of the energy resource is carried out on the basis of measuring states by affecting processes and parameters. In this case, the values of delays and errors in measuring and processing signals should not exceed the values at which there is a fundamental possibility of influencing energy processes in conditions of irreversible energy dissipation.

The requirements for the speed of the measuring devices are determined by the type of current and the dynamic characteristics of the converter. For systems with thyristor converters, the measurement time must not exceed a value equal to the period or part of the network period. This means that the speed of the compensating devices must provide an impact on the process with a discreteness not exceeding the period or part of the network period.

Traditional control systems for compensating devices implements the principle of regulation by deviation and contain the following main elements: the adjustable parameter regulator, the measuring transducer, the comparison element, the regulating and the actuating devices. 
The speed of the compensating device is determined by the time of sequential signal processing in the control loop and is equal to several periods of the supply network (Taylor et al., 1994).

The paper considers a voltage loss compensation system based on the perturbation regulation principle, which provides an increased performance.

\section{Compensator control algorithm}

In Fig. 1 shows a simplified equivalent single-line diagram of an electrical line with an active resistance $\mathrm{r}$ and an inductive impedance $\mathrm{x}$ providing load power. In Fig. 1 denotes: $\dot{E}$ - voltage of the power source; $\Delta \dot{U}$ - voltage drop in the power supply network; $\dot{I}=I_{a}+j I_{r}$ - current of the mains; $I_{a}$ - active current of the mains; $I_{r}$ - reactive current of the mains; $\dot{U}$ - voltage in the load node; $x_{c}$ - equivalent reactance of the compensating device; $z_{l}$ - complex load resistance. The reactive load current can be inductive or capacitive. The load can both consume electrical energy and recover it into the supply network.

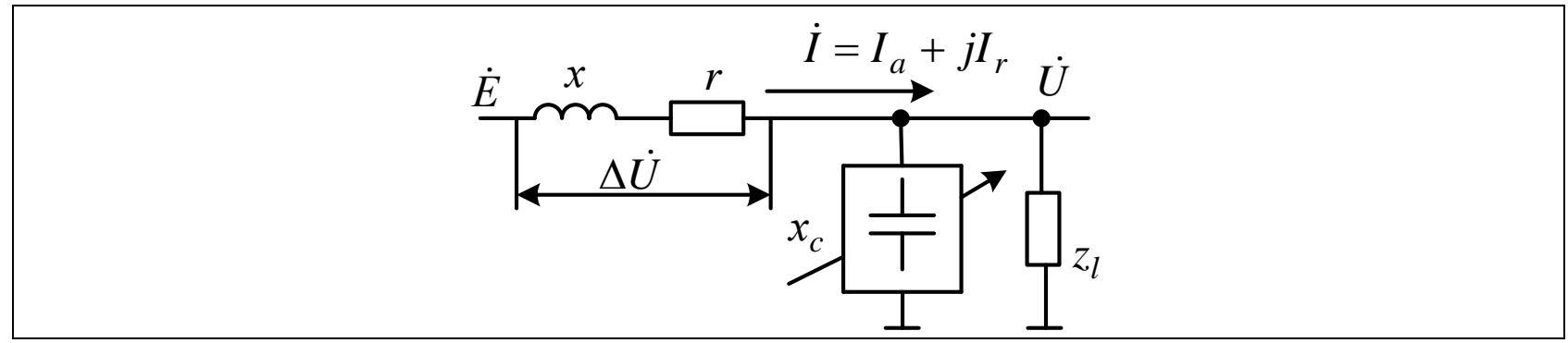

Fig. 1. Simplified circuit of electrical system

In Fig. 2 shows the vector diagrams of currents and voltages in the load node in the mode of consumption of active-inductive current. Denotes on the figure shows: $I_{r l}$ - reactive load current; $I_{c}$ - reactive current of the compensating device. The active current of the supply network is equal to the active load current $I_{a}=I_{a l}$. The sign of the reactive current is determined by its character: the inductive current (lagging behind the voltage) is negative, the capacitive (leading before the voltage) is positive. The positive active current corresponds to the energy consumption, the negative active current corresponds to the energy recuperation into the supply network.

Based on the vector diagram in Fig. 2, it is possible to form an equation for the effective stress values:

$$
E^{2}=\left(U+r I_{a l}-x I_{r}\right)^{2}+\left(r I_{r}+x I_{a l}\right)^{2} .
$$

Here $E$ - voltage in the power center.

The solution of equation $E=U$

taking into account relation (1) with respect to the reactive current supply gives the expression 


$$
I_{\mathrm{r}}=U \frac{x}{r^{2}+x^{2}} \pm \sqrt{\frac{U^{2} x^{2}}{\left(r^{2}+x^{2}\right)^{2}}-\frac{2 r I_{a l} U}{\left(r^{2}+x^{2}\right)}-I_{a l}^{2}}
$$

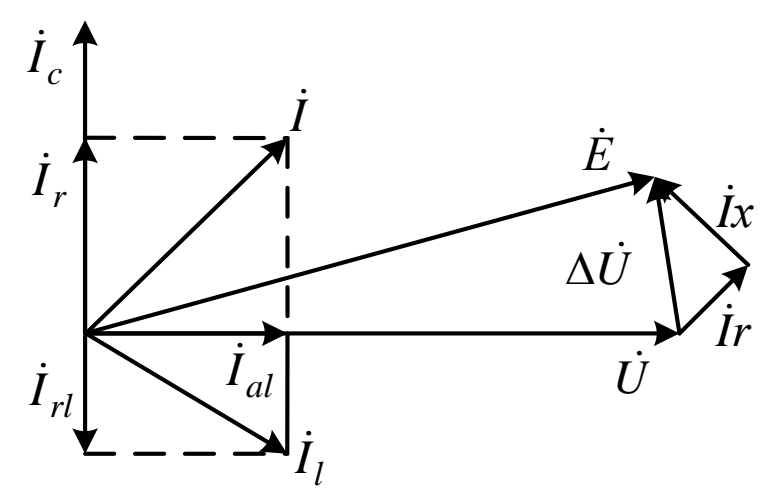

a

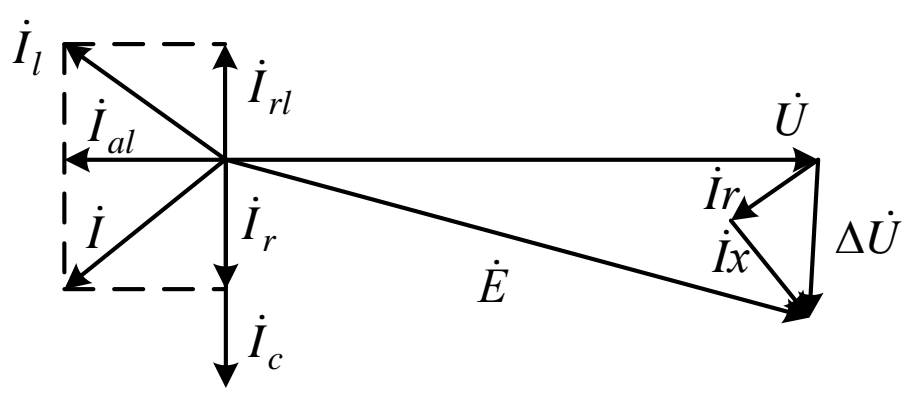

b

Fig. 2. Vector diagram of currents and voltages at consumption (a) and recuperation (b) of electric power.

To determine the sign (+ or - ) in the expression (2), we consider the case $I_{\mathrm{al}}=0$. Full compensation is provided at the $I_{r}=0$. Expression (2) at the $I_{a l}=0$ takes the form

$$
I_{r}=U \frac{x}{r^{2}+x^{2}} \pm U \frac{x}{r^{2}+x^{2}}
$$

It follows from equation (3) that in formula (2) of the physical essence of the process there corresponds the sign "-". Therefore, the solution of equation (1) is the expression

$$
I_{r}=U \frac{x}{r^{2}+x^{2}}-\sqrt{\frac{U^{2} x^{2}}{\left(r^{2}+x^{2}\right)^{2}}-\frac{2 r I_{a l} U}{\left(r^{2}+x^{2}\right)}-I_{a l}^{2}} .
$$

Therefore, if the reactive current of the supply network is set using the compensating device in accordance with equation (4), the voltage loss in the network will be completely compensated and the voltage on the load will be equal to the voltage of the power source $U=E$. 
In the case under consideration, the current of the compensator has a capacitive character and is equal to

$$
I_{c}=-\left(I_{r}+I_{r l}\right) .
$$

In Fig. 3 shows a vector diagram of currents and voltages in the electrical system for the case of an active-inductive load in the mode of energy recuperation into the supply network.

\section{A simplified control algorithm current compensator}

The disadvantage of the control algorithm according to the formula (4) is the need to measure the voltage, active and reactive currents and data on the parameters of the supply line. To derive a simplified algorithm, consider expression (1). Electrical networks are designed from the condition of allowable loss of voltage in the line, therefore, fairly the inequality

$$
\left(U+r I_{a l}-x I_{r}\right)^{2}>\left(r I_{r}+x I_{a l}\right)^{2} .
$$

Taking into account inequality (6), equation (1) takes the form

$$
E \approx\left(U+r I_{a l}-x I_{r}\right) .
$$

The solution of equation (7) with respect to the reactive current of the supply network gives the expression

$$
I_{r} \approx \frac{r}{x} I_{a l}
$$

It follows from equation (8) that if the reactive current $I_{r}$ in the line is maintained in proportion to the active load current $I_{a l}$, the voltage loss in the supply network is compensated. The coefficient of proportionality is equal to the ratio of the active and reactive resistances of the supply line and does not depend on its length. To implement the control system, it is sufficient to measure only the active and reactive load currents. The proportionality factor in Eq. (8) is determined from the reference data for the line resistances of a particular line.

The active resistance of the line changes with temperature. This leads to a change in the proportionality coefficient in Eq. (8). To correct the change in line resistance in equation (8), we can use the temperature correction and write it in the form

$$
I_{r} \approx \frac{r_{0}(1+\alpha \cdot \Delta \theta)}{x} I_{a l} .
$$


Here $r_{0}$ - the initial value of the ambient temperature for which the linear resistance of the line is indicated; $\alpha$ - temperature coefficient of resistance for a material of conductors $\left(\alpha_{C u}=4,3 \cdot 10^{-3} K^{-1}\right.$ for copper and $\alpha_{A l}=4,2 \cdot 10^{-3} K^{-1}$ for aluminum); $\Delta \theta$ - a change in the ambient temperature relative to the initial value.

The power factor for controlling the reactive current in accordance with Eq. (8) is determined by formula

$$
\lambda=\cos \varphi \approx \frac{I_{a l}}{\sqrt{I_{r}^{2}+I_{a l}^{2}}}=\frac{I_{a l}}{\sqrt{\left(\frac{r}{x} I_{a l}\right)^{2}+I_{a l}^{2}}}=\frac{x}{\sqrt{r^{2}+x^{2}}} .
$$

Equation (10) determines the modulus of the power factor. The current in the line can be leading or lagging in phase from the voltage.

Example. The process unit at the enterprise receives power from the substation using a $5 \mathrm{~km}$ long line, the active and inductive line resistances are equal to $r=5 \mathrm{Ohms} ; x=5$ Ohms. The voltage at the substation is $6300 \mathrm{~V}$. Active load current $I_{a l}=100 \mathrm{~A}$; reactive load current $I_{r l}=-50 \mathrm{~A}$ (lagging current).

In accordance with equation (4), the voltage on the load is equal to the voltage at the substation with the reactive current in the supply network $I_{r}=119 \mathrm{~A}$. The capacitance current of the compensator in accordance with equation (5) is then equal to $I_{c}=169 \mathrm{~A}$. Using the simplified algorithm (8), the reactive current in the supply network is $I_{r}=100 \mathrm{~A}$. The voltage on the load is $6220 \mathrm{~V}$. The error of voltage stabilization is $1.3 \%$.

\section{Implementation of the compensation system}

To implement the considered voltage loss compensation algorithms, high-speed devices are used, for example, compensators with thyristor regulation of the reactor current and a capacitor bank connected in parallel (Figure 3, a) and compensators based on transistor inverters (Figure 3, b). Compensators must provide control of capacitive and inductive currents.

The control time is determined by the sum of the active current measurement time and the reaction time of the compensator. The exact measurement of the active current is carried out during the period of the mains voltage. With the use of special algorithms for signal processing, it is possible to parallelize and generate a control signal for the compensator. In this case, it is possible to achieve a compensator speed of $5 \mathrm{~ms}$.

The scheme of the system for compensation of voltage loss in the supply network is shown in Fig. 4. Signals from primary current and voltage converters (current and voltage transformers) are converted by means of high-speed active and reactive current sensors into digital signals proportional to $I_{a l}$ and $I_{r l}$. 
The controller performs the processing of the output signals of active and reactive current and temperature sensors: calculates the required value of the reactive line current in accordance with equation (9) and the required compensator current according to equation (5).

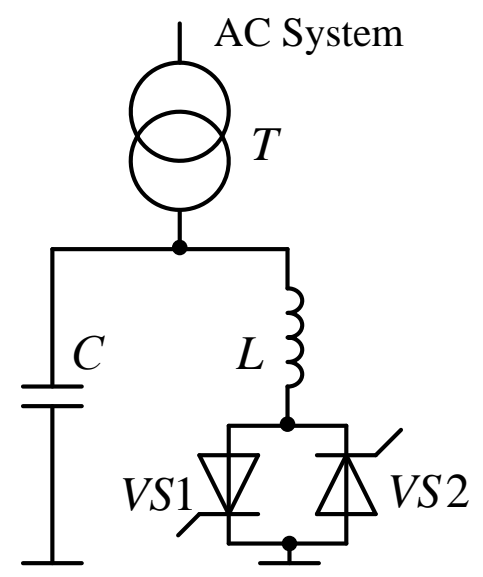

a

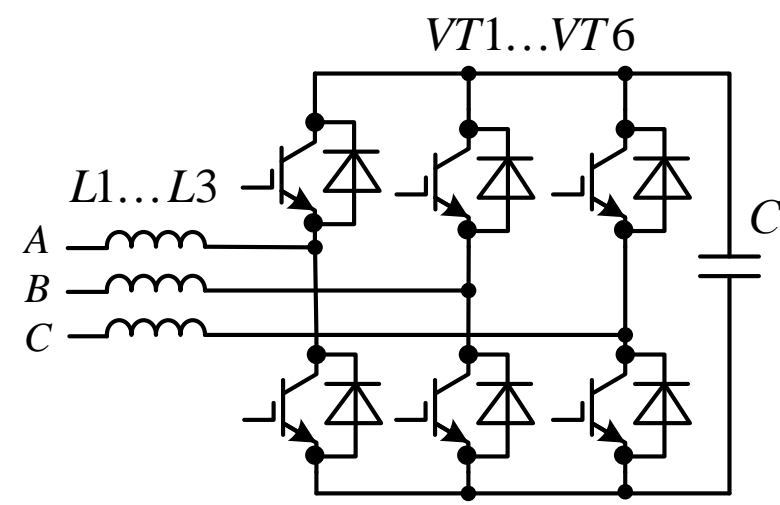

$\mathrm{b}$

Fig. 3. Schematics of high-speed compensators: thyristor-reactor (a) and transistor inverter (b)

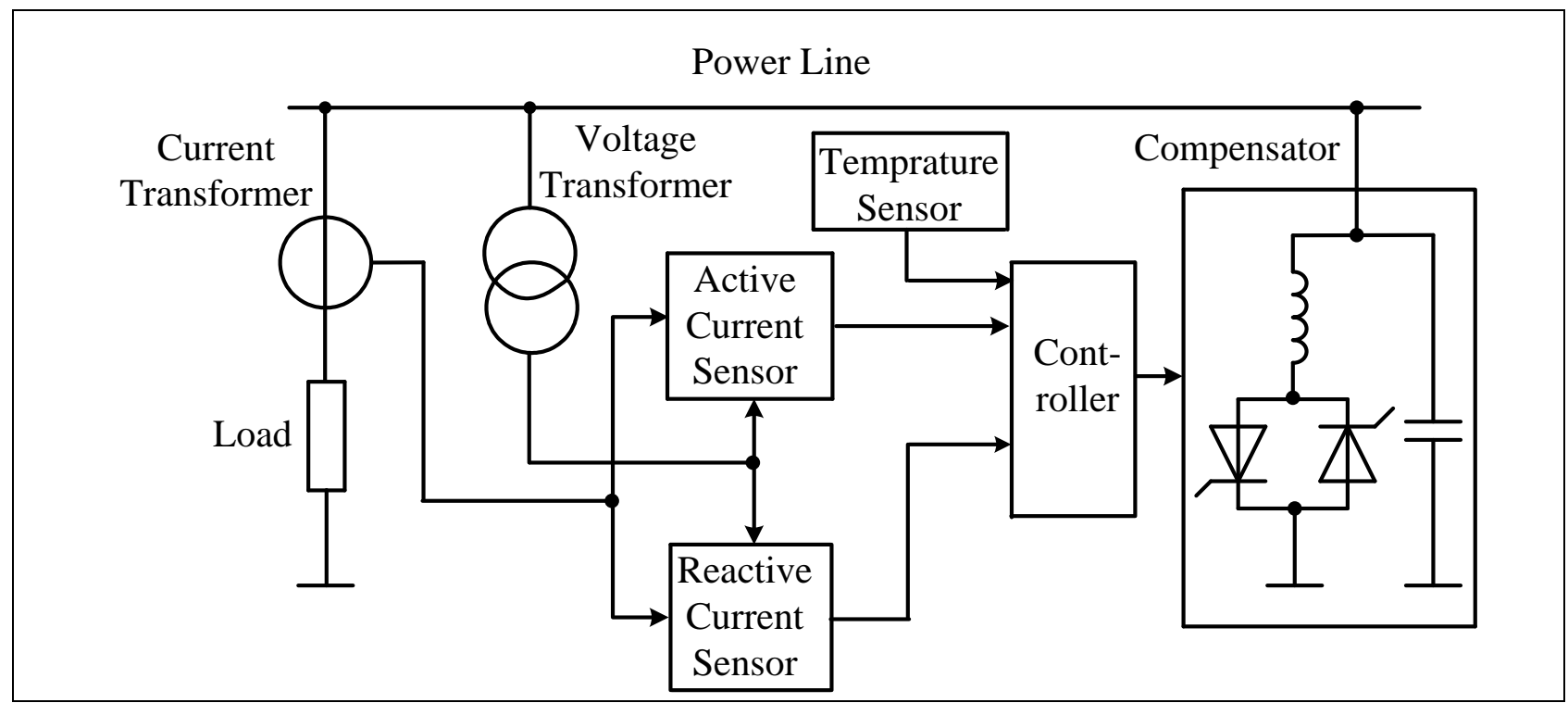

Fig. 4. Schematics of control system

\section{Conclusion}

The voltage stabilization algorithms considered above are based on an analytical solution of the problem of determining the regime in an electrical system. Compensation of voltage loss in the supply line is ensured in all modes of operation: with energy consumption and recuperation. A simplified algorithm for compensation of voltage loss provides for maintaining the reactive current in the line in proportion to the active load current. In this case, only the ratio of the line values of the active and reactive resistances is used to implement the system, which is a constant for the line. 
The change in the line resistance when the ambient temperature is changed is taken into account by the correction coefficient. The control time in the system is determined by the measurement time and the transient time in the compensator. When using a high-speed compensator, this time is 1 period of the mains supply.

\section{References}

Dixon, J. et al. (2005). Reactive power compensation technologies, State- of-the-Art Review, Proceedings of the IEEE, Vol. 93, No. 12, December 2005, pp. 2144 2164, doi: 10.1109 / JPROC.2005.8599937.

Malafeev, S.I. \& Novgorodov, A.A. (2016). Design and implementation of electric drives and control systems for mining excavators, Russian Electrical Engineering. October 2016, Volume 87, Issue 10: 560-565. doi: 10.3103 / S1068371216100035. Malafeev, S.I. \& Serebrennikov, N.A. (2006). Mechatronic systems of the one-paddle excavators, Fifth International Congress. Mechanical Engineering Technologies 04, September 20-23.2006. Procedings, Vol. 1, pp. 7-10, Varna, Bulgaria.

Morley, L.A. (1990). Mine Power Systems. Information Circular 9258 (United States Bureau of Mines). - Washington, DC, 1990, 437 p.

Pandit, P. et al. (2010). Real-Time Power Quality Measurements From a Conventional AC Dragline, IEEE Transactions on Industry Applications, Vol. 46, No. 5, September / October 2010, pp. 1755 - 1763; doi 10.1109/ TIA.2010.2057470. Rogobete, M. \& Dumitrascu, M. (2016). Artificial Intelligence in Optimal Repartition of the Reactive Power, Chapter 12 in DAAAM International Scientific Book 2016, pp. 121-134, B. Katalinic (Ed.), Published by DAAAM International. ISBN 978-3902734-09-9, ISSN 1726-9687, Vienna, Austria; doi:10.2507/daaam.scibook.2016.12 Singh, H., Sharma, D. (2015). Reactive Compensation Capability of Fixed Capacitor Controlled Reactor for Load Power Factor Improvement: A Review, International Journal of Scientific \& technology Research. Vol. 4, ISSUE 01, pp. 225-228, January 2015.

Taylor, C.W. et al. (1994). Static Var Compensator Models for Power Flow and Dynamic Performance Simulation. IEEE Transactions on Power Systems, Vol. 9, No. 1, February 1994, pp. 229 - 240.

Vasileviccs, O. \& Rankis, I. (2012). Principles of Realization of Control System for a Compensator of Reactive Power on Base of Gate Commutated Thyristors. Power and Electrical Engineering, 2012, No. 30, pp. 41 - 44. 